\title{
Effect of heat-shock protein B7 on oxidative stress in adipocytes from preruminant calves
}

\author{
Xudong Sun, ${ }^{1}$ Xiaobing Li, ${ }^{1}$ Hongdou Jia, ${ }^{1}$ Juan J. Loor, ${ }^{2}$ Ryan Bucktrout, ${ }^{2}$ Qiushi Xu, ${ }^{1}$ Yazhe Wang, ${ }^{1}$ \\ Xin Shu, ${ }^{1}$ Jihong Dong, ${ }^{1}$ Rankun Zuo, ${ }^{3}$ Liangyu Yang, ${ }^{4}$ Guowen Liu, ${ }^{1}$ and Xinwei Li ${ }^{1 *}$ \\ ${ }^{1}$ Key Laboratory of Zoonosis Research, Ministry of Education, College of Veterinary Medicine, Jilin University, 5333 Xi'an Road, Changchun, \\ 130062, Jilin, China \\ ${ }^{2}$ Mammalian NutriPhysioGenomics, Department of Animal Sciences and Division of Nutritional Sciences, University of Illinois, Urbana 61801 \\ ${ }^{3}$ College of Veterinary Medicine, Qingdao Agricultural University, Qingdao, 266109, Shandong, China \\ ${ }^{4}$ College of Veterinary Medicine, Yunnan Agricultural University, Kunming, 650201, China
}

\section{ABSTRACT}

Dairy cows with ketosis display excessive lipolysis in adipose tissue. Heat-shock protein B7 (HSPB7), a small heat-shock protein, plays important roles in mediating cytoprotective responses to oxidative stress in rodent adipose tissue. Accordingly, it is assumed that HSPB7 may also play important roles in the antioxidant response in adipose tissue of ketotic cows. Therefore, the aim of this study is to investigate (1) the redox state of adipose tissue in ketotic cows and (2) the role and mechanism of HSPB7 on the regulation of oxidative stress in adipocytes from preruminant calves. An in vivo study consisting of 15 healthy and 15 clinically ketotic cows was performed to harvest subcutaneous adipose tissue and blood samples. In addition, adipocytes isolated from calves were treated with different concentrations of $\mathrm{H}_{2} \mathrm{O}_{2}(0,12.5,25,50,100$, or 200 $\mu M)$ for $2 \mathrm{~h}$, transfected with adenovirus-mediated overexpression of HSPB7 for $48 \mathrm{~h}$, or transfected with small interfering RNA of HSPB7 for $48 \mathrm{~h}$ followed by exposure to $\mathrm{H}_{2} \mathrm{O}_{2}(200 \mu M)$ for $2 \mathrm{~h}$. Serum concentrations of nonesterified fatty acids and $\beta$-hydroxybutyrate were greater in cows with clinical ketosis, whereas serum concentration of glucose was lower. Compared with healthy cows, the malondialdehyde content was greater but the activity of glutathione peroxidase and superoxide dismutase was lower in adipose tissue of clinically ketotic cows. The abundance of HSPB7 and nuclear factor, erythroid 2 like 2 (NFE2L2) was greater in adipose tissue of clinically ketotic cows. In vitro, $\mathrm{H}_{2} \mathrm{O}_{2}$ treatment induced the overproduction of reactive oxygen species and malondialdehyde, and inhibited the activity of antioxidant enzymes glutathione peroxidase

Received September 20, 2018.

Accepted February 10, 2019.

*Corresponding author: lixinwei100@126.com and superoxide dismutase in adipocytes from preruminant calves. The low concentration of $\mathrm{H}_{2} \mathrm{O}_{2}(12.5,25$, and $50 \mu M$ ) increased the abundance of HSPB7 and NFE2L2, but high concentrations of $\mathrm{H}_{2} \mathrm{O}_{2}$ (100 or 200 $\mu M$ ) reduced the abundance of HSPB7 and NFE2L2. The overexpression of HSPB7 improved the $\mathrm{H}_{2} \mathrm{O}_{2}$ induced oxidative stress in adipocytes via increasing the abundance of NFE2L2 and its downstream target genes heme oxygenase-1 (HMOX1) and NADH quinone oxidoreductase 1 (NQO1). Knockdown of HSPB7 markedly inhibited the expression of NFE2L2, HMOX1, and NQO1 and further exacerbated $\mathrm{H}_{2} \mathrm{O}_{2}$-induced oxidative stress. Overall, these results indicate that activation of the HSPB7-NFE2L2 pathway increases cellular antioxidant capacity, thereby alleviating oxidative stress in bovine adipocytes.

Key words: adipocytes, HSPB7, oxidative stress, NFE2L2

\section{INTRODUCTION}

Ketosis is a major metabolic disorder of dairy cows in early lactation, a time during which cows often display a state of negative energy balance (NEB) induced by a low intake of DM and an increase in demands for energy (Roche et al., 2013). Severe NEB initiates fat mobilization of adipose tissue and increases the blood concentration of nonesterified fatty acids (NEFA) and BHB (Loor et al., 2007). It is clear that the intense adipose mobilization play promoting roles in the onset and progression of the ketosis (Grummer, 1993; White, 2015). Metabolic adaptations to NEB trigger catabolic pathways of adipose tissue and increase the systemic reactive oxygen species (ROS) production (Bernabucci et al., 2005; Pedernera et al., 2010), but it is currently unclear that oxidative stress exists in the adipose tissue of ketotic cows. When the antioxidant defenses are unable to neutralize the excessive ROS, oxidative stress 
can be induced. Increasing evidence demonstrates that dairy cows with ketosis display systemic (Sahoo et al., 2009; Li et al., 2016; Youssef and El-Ashker, 2017) and hepatic (Du et al., 2017) oxidative stress. However, the redox state of adipose tissue in ketotic cows remains unclear.

Small heat-shock proteins are a family of molecular chaperones (Yang et al., 2011), exerting housekeeping functions in normal cell metabolism as well as protective functions under stress conditions (Verschuure et al., 2003). Heat-shock protein B7 (HSPB7), a member of the small heat-shock proteins family, is preferentially expressed in cardiovascular, skeletal muscle and adipose tissue (Yang et al., 2011). The expression of HSPB7 mRNA was increased in the white adipose tissue of obese rats (Krief et al., 1999). Previous studies also demonstrated that high expression of heat shock protein 70 represents an autoprotective mechanism for biological stress, especially for oxidative stress, in mouse RIF1 cells and multidrug-resistant human breast carcinoma (MCF-7/ADR) cells and in skeletal muscle, heart, and liver (Salo et al., 1991; Gomer et al., 1996; Morimoto and Santoro, 1998; Lee and Corry, 1998). Collectively, these findings indicate that high expression of HSPB7 may also be an adaptation mechanism to oxidative stress in adipose tissue of obese rodents and humans.

To our knowledge, the abundance and role of HSPB7 in the adipose tissue of ketotic cows has not been characterized. In addition to heat shock protein, the nuclear factor, erythroid 2 like 2 (NFE2L2) also has a crucial role in the antioxidant response in humans and rodents (Karttunen et al., 2018; Sherif, 2018). Activation of NFE2L2 initiates transcription of the various antioxidant genes including heme oxygenase-1 (HMOX1), NADH quinone oxidoreductase 1 (NQO1), glutathione peroxidase (GSH-Px), and superoxide dismutase (SOD), which together enhance cellular antioxidant capacity (Jung and Kwak, 2010). However, it is unclear whether HSPB7 is associated with stress-induced
NFE2L2 activation or the regulation of oxidative stress (or both) in the adipose tissue of ketotic cows.

Because of the antioxidant role of the HSPB7 and NFE2L2 via regulating of antioxidant genes transcription in adipose tissue of rodents and humans, we hypothesized that HSPB7 and NFE2L2 may also play important roles in mediating cytoprotective responses to oxidative stress in adipose tissue of ketotic cows. Therefore, the aim of this study is to investigate (1) the redox state of adipose tissue in ketotic cows and (2) the role and mechanism of HSPB7 on the regulation of oxidative stress in adipocytes from preruminant calves.

\section{MATERIALS AND METHODS}

\section{Animals}

The study protocol was approved by the Ethics Committee on the Use and Care of Animals at Jilin University (Changchun, China). Dairy cows were selected from a 7,000-cow dairy farm located in Changchun City, Jilin Province, China. All cows received a routine physical examination to ensure absence of other co-morbidities. Cows had ad libitum access to the same diet (Supplemental Table S1; https://doi.org/10.3168/ jds.2018-15726). We chose lactating Holstein cows with a similar number of lactations (median $=3$, range $=$ 2 to 4 ) and DIM (median $=6 \mathrm{~d}$, range $=3$ to $10 \mathrm{~d}$ ). The cows were classified as suspected clinical ketosis by veterinarians if feed intake, milk yield, or both were reduced and a nitroprusside test for ketone bodies in milk was positive (Du et al., 2018). Subsequently, the blood concentration of $\mathrm{BHB}$ in these cows was measured. According to the clinical symptoms and serum BHB concentrations (Itle et al., 2015; Du et al., 2018), 15 cows with serum BHB concentrations greater than $3 \mathrm{~m} M$ and 15 control cows with serum BHB concentrations below $0.6 \mathrm{~m} M$ were selected. The basic description of the cows is reported in Table 1.

Table 1. Body weight; milk production; DMI; and serum glucose, nonesterified fatty acids (NEFA), and BHB of healthy and clinically ketotic cows

\begin{tabular}{lcc}
\hline & \multicolumn{2}{c}{${\text { Median; } \text { IQR }^{1}}$} \\
\cline { 2 - 3 } Item & Control $(\mathrm{n}=15)$ & Clinical ketosis $(\mathrm{n}=15)$ \\
\hline BW $(\mathrm{kg})$ & $(657 ; 22.41)$ & $(665 ; 28.33)$ \\
Milk production $(\mathrm{kg}$ of milk/cow per day) & $(31.2 ; 2.5)$ & $(26.4 ; 2.1)^{*}$ \\
DMI $(\mathrm{kg} / \mathrm{d})$ & $(21.4 ; 1.6)$ & $(20.6 ; 1.9)$ \\
Serum glucose $(\mathrm{m} M)$ & $(4.19 ; 0.32)$ & $(1.22 ; 0.19)^{* *}$ \\
Serum NEFA $(\mathrm{m} M)$ & $(0.21 ; 0.013)$ & $(3.57 ; 0.325)^{* *}$ \\
Serum BHB $(\mathrm{m} M)$ & $(0.37 ; 0.025)$ & \\
${ }^{1} \mathrm{IQR}=$ interquartile range. & & \\
$* P<0.05 ; * * P<0.01$. & & \\
$*$
\end{tabular}


Blood samples were collected on 3 consecutive days at the same hour every day via jugular venipuncture (no anticoagulant). The first blood sample was collected at the moment of clinical examination and then the other 3 samples harvested every $24 \mathrm{~h}$. The blood samples were collected between 0700 and $0800 \mathrm{~h}$ before feeding and the serum was separated after centrifugation at $3,500 \times g$ for 15 min at $4^{\circ} \mathrm{C}$ and stored at $-80^{\circ} \mathrm{C}$ until analysis. Cows had access to a constant supply of fresh water and were milked twice daily at 0800 and $1530 \mathrm{~h}$. Milk yield was recorded electronically.

Subcutaneous adipose tissue (approximately $3 \mathrm{~g}$ ) biopsies from each of the 15 cows were taken according to published procedures (Zachut et al., 2017). Briefly, the biopsy site, a $5 \times 5 \mathrm{~cm}$ area of skin at the tailhead, was prepared by clipping, washing, and disinfecting. The biopsy site was anesthetized and aseptic techniques were used in making a 1.5 - to 2.5 -cm scalpel incision through the skin and subcutaneous tissue. Adipose samples were captured with tweezers and cut off with scissors, tissue samples were washed with saline, and then snap-frozen in liquid nitrogen and stored at $-80^{\circ} \mathrm{C}$.

After $3 \mathrm{~d}$ of sample collection, the ketotic cows receive combined therapy with glucocorticoids and oral glucogenic supplements, propylene glycol (PG), according to published procedures (van der Drift et al., 2015). Briefly, after collection of samples, cows were all treated with $250 \mathrm{~mL}$ of PG (Eurovet Animal Health) orally twice daily for $3 \mathrm{~d}$ and single intramuscular injections of $1 \mathrm{mg} / 50 \mathrm{~kg}$ of BW dexamethasone-21-isonicotinate (Voren Suspension; Boehringer Ingelheim). Metabolic blood variables were monitored for $6 \mathrm{~d}$. The BHB concentrations in blood decreased in all cows after treatment, indicating a good therapeutic effect.

\section{Determination of Blood Biomarkers}

Concentrations of glucose, BHB, and NEFA in serum were determined using a Hitachi 7170 autoanalyzer (Hitachi, Tokyo, Japan) with commercially available kits (BHB: cat. no. RB1008; NEFA: cat. no. FA115; glucose: cat. no. GL3815; Randox Laboratories, Crumlin, UK).

\section{Isolation of Primary Preadipocytes}

Adipocytes were isolated according to published procedures (Yin et al., 2015; Zhang et al., 2018). Five healthy Holstein calves (1 d old, female, 30-40 kg) were anesthetized with xylazine and ketamine and maintained with halothane and oxygen in a semi-closed circle system. Lactated Ringer's solution was administered intravenously during the procedure. The calves were positioned in dorsal recumbency and prepared for aseptic surgery, a 15 -cm abdominal incision was made extending caudally from the costal margin. The adipose tissue from the peritoneal omentum and mesentery were captured with tweezers and cut off with scissors under sterile conditions. The peritoneal omentum and mesentery were sutured with surgical gut sutures. After sample collection, the incision was closed in 5 layers (internal rectus sheath and peritoneum, rectus abdominus muscle, external rectus sheath, subcutaneous tissue, and skin), each in a simple continuous suture pattern. Additional postoperative management included ampicillin $(20 \mathrm{mg} / \mathrm{kg}$ i.m. twice daily) for $3 \mathrm{~d}$ and daily examination including incisional inspection, behavior, appetite, urination, and defecation. Calves were confined until suture removal 10 to $14 \mathrm{~d}$ following surgery and then returned to the farm and routine management in dairy farm. The resulting tissue was rinsed in sterile PBS containing penicillin $(2,500 \mathrm{U} / \mathrm{mL})$ and streptomycin $(2,500 \mathrm{mg} / \mathrm{mL})$ to remove adherent blood. The fascia and blood vessels visible in the tissue were carefully peeled away, and the resulting tissue was cut into small pieces of approximately $1 \mathrm{~mm}$ and digested using Dulbecco's modified Eagle medium (DMEM)/F12 digestion solution containing collagenase type I (1 mg/ $\mathrm{mL}$, Sigma-Aldrich, St. Louis, MO) at $37^{\circ} \mathrm{C}$ in a slightly shaking water bath for $1 \mathrm{~h}$. The mixture was removed from the digested tissue fluid through a $80-\mu \mathrm{m}$ cell filter and the filtrate was centrifuged at $175 \times g$ at room temperature for $10 \mathrm{~min}$. The residual erythrocytes were removed by adding ACK lysis buffer (Beyotime Institute of Biotechnology, Jiangsu, China) into the precipitate and centrifuging at $175 \times g$ at room temperature for $10 \mathrm{~min}$. The supernatant was discarded, and the pellet was resuspended with basic culture medium (BCM), which was DMEM/F12 with $10 \%$ fetal bovine serum and $1 \%$ penicillin/streptomycin. After cell counting, the cell suspension was adjusted to a concentration of $1 \times 10^{4} / \mathrm{cm}^{2}$ and inoculated in a cell culture flask. The culture was then incubated at $37^{\circ} \mathrm{C}$ and $5 \% \mathrm{CO}_{2}$ in a cell incubator for $24 \mathrm{~h}$. The medium was replaced to remove nonadherent cells and tissue residues. The BCM was replaced every other day.

\section{Cell Culture and Treatment}

Adipocytes were differentiated as described previously (Yin et al., 2015; Zhang et al., 2018). To induce differentiation of preadipocytes into mature adipocytes, primary cells were seeded in cell culture plates. The $\mathrm{BCM}$ was discarded after cell aggregation reached $\sim 70 \%$. Then, freshly prepared differentiation culture medium 1 , which was a final concentration of $0.5 \mathrm{~m} M$ IBMX (I-7018 Sigma-Aldrich), $1 \mu M$ dexamethasone (D-4902 
Sigma-Aldrich), and $1 \mu \mathrm{g} / \mathrm{mL}$ insulin (I-5500 SigmaAldrich) in BCM, was used to induce differentiation. After $48 \mathrm{~h}$ of culture, differentiation culture medium 1 was discarded and replaced by differentiation culture medium 2 , which was a final concentration of $1 \mu \mathrm{g} / \mathrm{mL}$ insulin in BCM, to maintain the differentiation culture. After $48 \mathrm{~h}$ of culture, differentiation culture medium 2 was discarded and replaced by BCM (DMEM/F12 with $10 \%$ fetal bovine serum and $1 \%$ penicillin/streptomycin), the fresh BCM was replaced every other day to keep the culture until visible lipid droplets appeared in the cell, indicating that the cells have completed differentiation. This period lasted approximately $10 \mathrm{~d}$.

Adipogenic differentiation was evaluated using oil red $\mathrm{O}$ staining as an indication of intracellular lipid accumulation (Park et al., 2010). After induction of adipogenic differentiation as described above, cells were washed 3 times in PBS, fixed in 10\% formalin for 15 min, and washed a further 3 times in PBS. Subsequently, cells were washed in $60 \%$ (vol/vol) isopropanol for 2 min, stained with $0.5 \%$ (wt/vol) oil red O solution for 15 min, washed with $60 \%$ isopropanol and subsequently with PBS, and then counter-stained with hematoxylin before microscopy. After induction of adipogenic differentiation, the adipogenic efficiency was $96.2 \%$ and the representative images are shown in Supplemental Figure S1 (https://doi.org/10.3168/jds.2018-15726).

After the adipogenic induction, mature adipocytes were treated with $\mathrm{H}_{2} \mathrm{O}_{2}(0,25,50,100,200$, and 400 $\mu M$; 323381 Sigma-Aldrich) for $2 \mathrm{~h}$. For the transfection experiments, to overexpress or silence HSPB7, differentiated adipocytes were transfected with HSPB7 overexpression adenovirus (Ad-HSPB7), GFP negative control adenovirus (Ad-GFP), small interfering RNA (siRNA) for HSPB7, a negative siRNA control for $48 \mathrm{~h}$, and cells were then treated with $200 \mu M \mathrm{H}_{2} \mathrm{O}_{2}$ for $2 \mathrm{~h}$. The detailed grouping is described in the figure legends. The empty adenovirus vector (Ad-GFP) and HSPB7 overexpression adenovirus (Ad-HSPB7) were constructed by Gemma Genes (Shanghai, China). The siRNA was designed and synthesized by Gemma Genes based on the bovine HSPB7 mRNA sequence. The siRNA sequence was sense: 5'-CCUUCCGGACGGAGAUCAATT-3', and antisense: 5'-UUGAUCUCCGUCCGGAAGGTT-3'.

\section{Cell Viability Assay}

Cell viability was assessed by 3-(4,5-dimethylthiazol2-yl)-2,5-diphenyl tetrazolium bromide (MTT) cell proliferation and cytotoxicity assay kit (C0009, Beyotime Institute of Biotechnology, Jiangsu, China) according to the manufacturer's protocol. Briefly, adipocytes were plated on 96 -well multiplates at a density of $2 \times 10^{3}$ cells $/ \mathrm{mL}$, and then treated as aforementioned in Cell Culture and Treatment section. And then followed by treatment with $5 \mathrm{mg} / \mathrm{mL}$ of MTT for $4 \mathrm{~h}$ at $37^{\circ} \mathrm{C}$. Optical density was measured at $570 \mathrm{~nm}$ on a microplate reader (Tecan, Grödig, Austria). Results are presented as a percentage of the control values.

\section{Determination of ROS Generation}

The levels of intracellular ROS were confirmed using the peroxide sensitive fluorescent probe 2'7'-dichlorofluorescein diacetate (Beyotime Institute of Biotechnology). The adipocytes were exposed to serum-free DMEM/F12 medium containing $25 \mu M$ 2'7'-dichlorofluorescein diacetate at $37^{\circ} \mathrm{C}$ in the dark for $20 \mathrm{~min}$ and then washed 3 times with DMEM/F12. Cells were detached from the dish with $0.25 \%$ trypsin and washed twice with PBS. Then, the cells were resuspended with $\mathrm{BCM}$ in $1.5-\mathrm{mL}$ tubes and centrifuged at $1,000 \times g$ for 5 min at $4^{\circ} \mathrm{C}$. The supernatant was discarded, and the pellet was resuspended with fresh serum-free DMEM/ F12. Fluorescence was measured by flow cytometry (FACSCalibur, Becton Dickinson, Sunnyvale, CA).

\section{Detection of Oxidative Stress Indicators}

The activities of GSH-Px and SOD as well as the contents of malondialdehyde (MDA) in adipose tissue and adipocytes were determined using spectrophotometric diagnostic kits (GSH-Px, S0058; SOD, S0109; MDA, S0131; Beyotime Institute of Biotechnology), according to the manufacturer's protocols. In brief, adipose tissue specimens were crushed with a microthermal $\left(4^{\circ} \mathrm{C}\right)$ tissue grinder (Shanghai Gino Tech \& Trading Co. Ltd., Shanghai, China), diluted with ice-cold PBS, and then centrifuged at $12,000 \times g$ for $10 \mathrm{~min}$ at $4^{\circ} \mathrm{C}$. Adipocytes were collected with ice-cold PBS by scraping, and then centrifuged at $1,000 \times g$ for $10 \mathrm{~min}$ at $4^{\circ} \mathrm{C}$. Absorbance was detected at $340 \mathrm{~nm}$ (GSH-Px), $560 \mathrm{~nm}$ (SOD), and $532 \mathrm{~nm}$ (MDA) and was recorded with a $722 \mathrm{~N}$ spectrophotometer (Scientific Instrument Co. Ltd., Shanghai, China).

\section{RNA Isolation and Quantitative Reverse- Transcription PCR}

Total RNA was extracted with RNAiso Plus (TaKaRa Biotechnology Co. Ltd., Dalian, China) from calf adipocytes and adipose tissue. The RNA concentration and quality were measured using a K5500 MicroSpectrophotometer (Beijing Kaiao Technology Development Ltd., Beijing, China) and electrophoresis (1\% agarose 
gels). The RNA analysis by electrophoresis showed that the total RNA was of high quality, evident by the appearance of clear $28 \mathrm{~S}, 18 \mathrm{~S}$, and $5 \mathrm{~S}$ bands without significant degradation. According to MIQE guidelines (Bustin et al., 2009), the 1.8 to 2.0 of optical density (OD) at $260 \mathrm{~nm} / \mathrm{OD}_{280}$ ratio is the threshold for RNA quality. In our study, the $\mathrm{OD}_{260} / \mathrm{OD}_{280}$ ratio of the total RNA was determined to be 1.9 and met the specified purity requirements. Then $1 \mu \mathrm{g}$ of total RNA in each sample was reverse-transcribed to cDNA (TaKaRa Biotechnology Co. Ltd.) according to the supplier's protocol. The primers used were designed by Primer Express software 5.0 and the primer sequences are shown in Supplemental Table S2 (https://doi.org/10.3168/jds .2018-15726). The SYBR green plus reagent kit (Roche, Norwalk, CT) was used to prepare a $20-\mu \mathrm{L}$ mixture and mRNA abundance was detected with a 7500 Real-Time PCR System (Applied Biosystems, Waltham, MA). The reaction conditions were as follows: $95^{\circ} \mathrm{C}$ for $3 \mathrm{~min}$, followed by 40 cycles of $95^{\circ} \mathrm{C}$ for $15 \mathrm{~s}$ and $60^{\circ} \mathrm{C}$ for 1 min. Gene expression was determined by the $2^{-\Delta \Delta \mathrm{CT}}$ method. The cycles-to-threshold values of GAPDH, ubiquitin, and $\beta$-actin were not affected by different treatments (Supplemental Figure S2; https://doi.org/ 10.3168/jds.2018-15726); therefore, the relative expression of target genes was normalized to GAPDH, ubiquitin, and $\beta$-actin. For in vivo quantitative real-time PCR experiments, the PCR reaction was performed in triplicate for each sample ( $\mathrm{n}=15$ cows per group). For in vitro quantitative real-time PCR experiments, the PCR reaction was performed in triplicate from each of the 3 individual cell preparations.

\section{Western Blot Analysis}

Total protein was extracted from the biopsy adipose samples and cultured cells using a commercial protein extraction kit [250 $\mathrm{m} M$ Tris ( $\mathrm{pH} 7.5$ ), $40 \mathrm{~m} M \mathrm{NaCl}, 10$ $\mathrm{m} M$ EDTA, $5 \mathrm{~m} M$ NP-40, protease and phosphatase inhibitors; C510003, Sangon Biotech Co. Ltd., Shanghai, China] according to the manufacturer's instructions. The protein concentration was determined using the
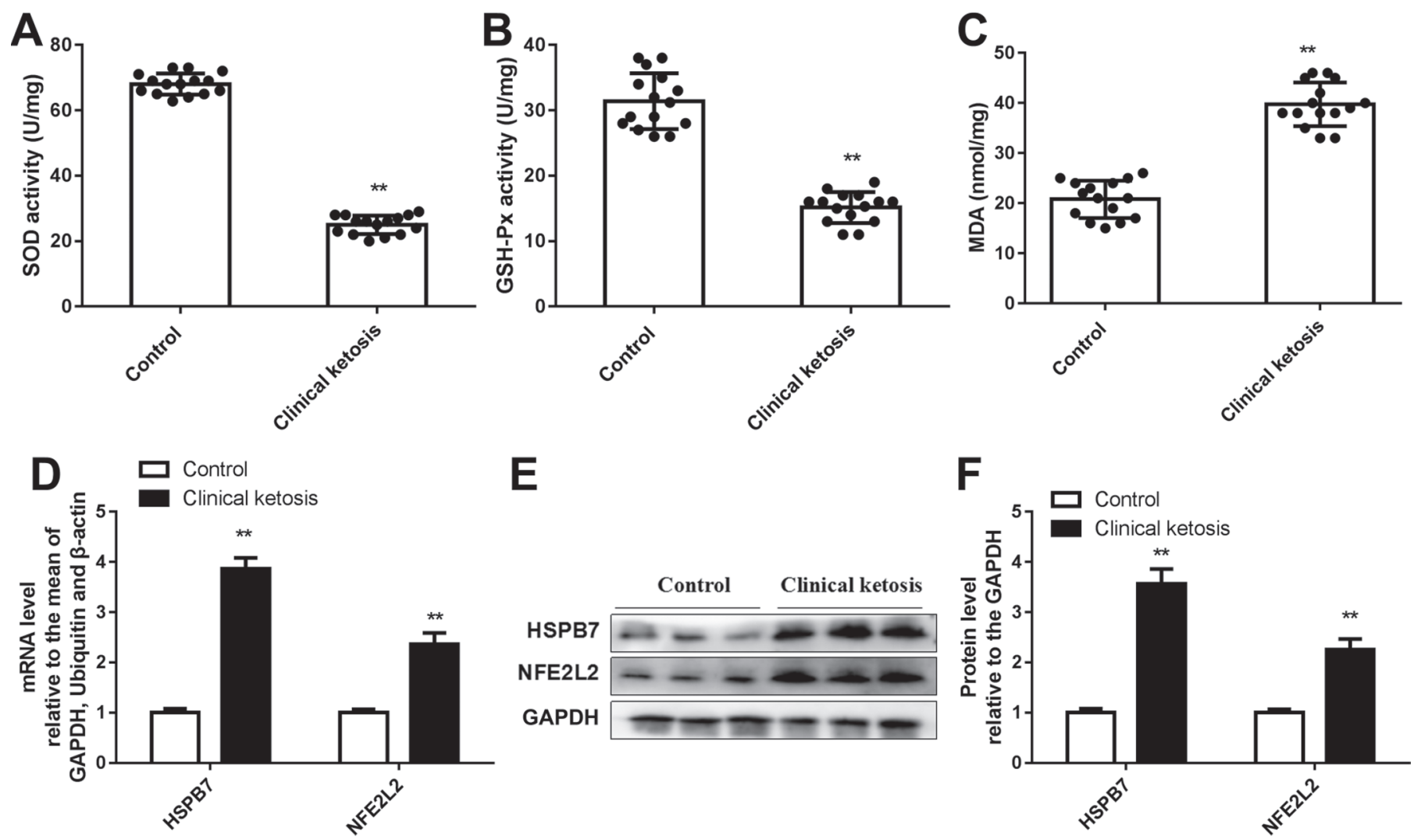

Figure 1. Dairy cows with ketosis displayed oxidative stress in adipose tissue, and increased abundance of heat-shock protein B7 (HSPB7) and nuclear factor, erythroid 2 like 2 (NFE2L2). (A) Superoxide dismutase (SOD) activity, (B) glutathione peroxidase (GSH-Px) activity, (C) malondialdehyde (MDA) content, (D) relative mRNA expression levels of HSPB7 and NFE2L2, (E) Western blot analysis of HSPB7 and NFE2L2, and (F) relative protein expression levels of HSPB7 and NFE2L2. The mRNA and protein expression levels of the ketosis group were normalized to the control group. Panels A-C were analyzed with Wilcoxon signed-rank test and expressed as the mean \pm SEM ( $\mathrm{n}=15$ per group). Panels D-F were analyzed with paired $t$-tests and expressed as the mean \pm SEM $\left(\mathrm{n}=15\right.$ per group). ${ }^{* *} P<0.01$. 
BCA Protein Assay Kit (P1511, Applygen Technologies). Thirty micrograms of protein was separated using SDS-PAGE with known molecular weight markers (Sangon Biotech Co. Ltd.). Subsequently, the protein was transferred onto $0.45 \mu \mathrm{m}$ polyvinylidene difluoride (PVDF) membranes. The PVDF membranes were incubated with primary antibodies against GAPDH (internal control; sc-59540, Santa Cruz Biotechnology Inc., Santa Cruz, CA; 1:5,000), HSPB7 (cat. no. Ab150390, Abcam, Cambridge, MA; 1:1,000), and NFE2L2 (cat. no. Ab31163, Abcam; 1:1,000) at $4^{\circ} \mathrm{C}$ overnight. Subsequently, the PVDF membranes were incubated with horseradish peroxidase-conjugated anti-mouse or anti-rabbit antibody (Boster, Wuhan,
China). Last, the immunoassay was performed using an enhanced chemiluminescent reagent (Pierce Biotechnology Inc., Chicago, IL). Densitometry analysis was performed with Image-Pro Plus 6.0 (Media Cybernetics Inc., Warrendale, PA) and target protein expression was normalized to GAPDH expression.

\section{Statistical Analysis}

The results are expressed as means \pm standard error of the mean of at least 3 independent experiments. Statistical analysis was conducted using SPSS 19.0 software (SPSS Inc., Chicago, IL). In the in vivo studies, data from quantitative real-time PCR and Western
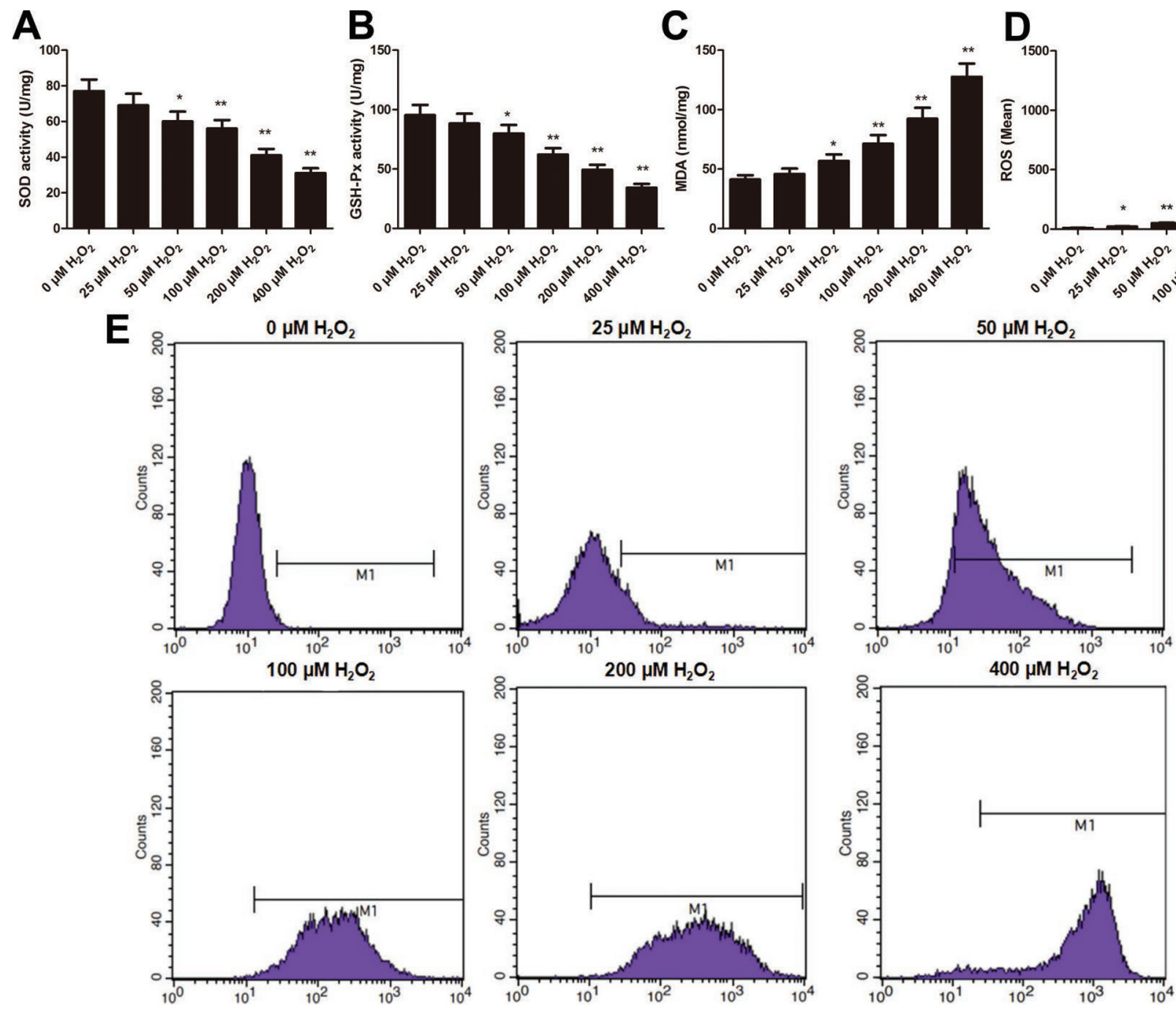

Figure 2. $\mathrm{H}_{2} \mathrm{O}_{2}$-induced oxidative stress in bovine adipocytes. Cells were treated with $0,25,50,100,200$, and $400 \mu M \mathrm{H}_{2} \mathrm{O}_{2}$ for $2 \mathrm{~h}$. (A) Superoxide dismutase (SOD) activity, (B) glutathione peroxidase (GSH-Px) activity, (C) malondialdehyde (MDA) content, and (D-E) reactive oxygen species (ROS) content. M1 = proportion of positive cells in 10,000 cells. Comparisons among groups were calculated using a 1-way ANOVA with subsequent Bonferroni correction. The data presented are the mean \pm SEM. ${ }^{*} P<0.05,{ }^{* *} P<0.01$. 
blotting were normally distributed and analyzed with paired $t$-tests; other data were nonnormally distributed and analyzed with Wilcoxon signed-rank test. In the vitro studies, comparisons among groups were analyzed using the 1-way ANOVA with subsequent Bonferroni correction. A $P$-value $<0.05$ was considered statistically significant, and a $P$-value $<0.01$ was considered highly significant.

\section{RESULTS}

\section{Increased Oxidative Stress and HSPB7 and NFE2L2 Abundance in Adipose Tissue of Cows with Clinical Ketosis}

The activity of the antioxidant enzymes SOD and GSH-Px was lower in adipose tissue of cows with clinical ketosis than in control cows $(P<0.01$, Figure $1 \mathrm{~A}$ and B). Conversely, the level of MDA in adipose tissue of cows with clinical ketosis was greater than in control cows $(P<0.01$, Figure $1 \mathrm{C})$. The mRNA and protein abundance of HSPB7 and NFE2L2 was greater in adipose tissue of the cows with clinical ketosis than in control cows $(P<0.01$, Figure 1D-F $)$.

\section{Effects of $\mathrm{H}_{2} \mathrm{O}_{2}$ on Oxidative Stress and the Abundance of the HSPB7 and NFE2L2 Pathway in Bovine Adipocytes}

As shown in Supplemental Figure S3 (https://doi .org/10.3168/jds.2018-15726), 25 to $200 \mu M \mathrm{H}_{2} \mathrm{O}_{2}$ did not have significantly decreased cell viabilities, whereas $400 \mu M \mathrm{H}_{2} \mathrm{O}_{2}$ significantly decreased cell viabilities $(P$ $<0.05$, Supplemental Figure S3A; https://doi.org/10 $.3168 /$ jds.2018-15726). The SOD and GSH-Px activity decreased in a $\mathrm{H}_{2} \mathrm{O}_{2}$ dose-dependent manner and was lower in the 50 to $400 \mu M$ cultures than in the control $(P<0.05$ and $P<0.01$, respectively, Figure $2 \mathrm{~A}$ and B). In contrast, the levels of MDA and ROS had an opposite trend and were greater in the 50 to $400 \mu M$ cultures $(P<0.05$ and $P<0.01$, respectively, Figure $2 \mathrm{C}-\mathrm{E})$. The mRNA and protein abundance of HSPB7 and NFE2L2 was greater with 25, 50, and $100 \mu M \mathrm{H}_{2} \mathrm{O}_{2}$ but was lower with 200 and $400 \mu M$ than in the control $(P<0.05$ and $P<0.01$, respectively, Figure $3 \mathrm{~A}-\mathrm{E})$. Furthermore, the mRNA abundance of NFE2L2 downstream target genes HMOX1 and NQO1 had a similar trend $(P<0.05$ and $P<0.01$, respectively, Figure $3 \mathrm{~F}$ and $\mathrm{G})$.
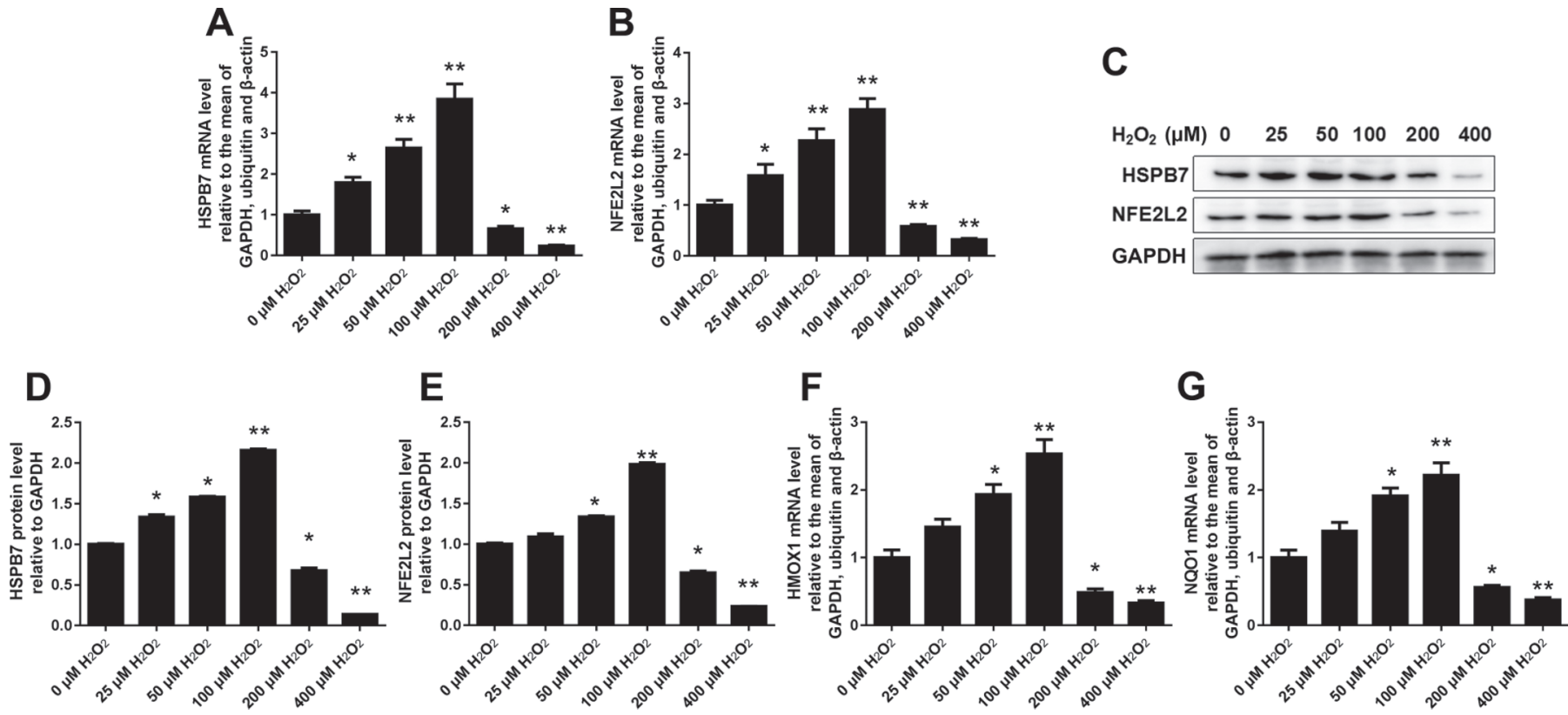

Figure 3. Effect of $\mathrm{H}_{2} \mathrm{O}_{2}$ on heat-shock protein B7 (HSPB7) and nuclear factor, erythroid 2 like 2 (NFE2L2) abundance in bovine adipocytes. Cells were treated with $0,25,50,100,200$, and $400 \mu M \mathrm{H}_{2} \mathrm{O}_{2}$ for $2 \mathrm{~h}$. (A) Relative mRNA expression level of HSPB7, (B) relative mRNA expression level of NFE2L2, (C) Western blot analysis of HSPB7 and NFE2L2, (D) relative protein expression levels of HSPB7, (E) relative protein expression levels of NFE2L2, (F) relative mRNA expression level of heme oxygenase-1 (HMOX1), and (G) relative mRNA expression level of NADH quinone oxidoreductase 1 (NQO1). The data of the $0 \mu M \mathrm{H}_{2} \mathrm{O}_{2}$ group were used to normalize the data of each treatment group. Comparisons among groups were calculated using a 1-way ANOVA with subsequent Bonferroni correction. The data presented are the mean \pm SEM. ${ }^{*} P<0.05,{ }^{* *} P<0.01$. 


\section{Effects of HSPB7 Overexpression on Oxidative Stress in Bovine Adipocytes}

The mRNA and protein abundance of HSPB7 in the Ad-HSPB7 group was greater than in the control group $(P<0.01$, Figure $4 \mathrm{~A}, \mathrm{C}$, and $\mathrm{D})$. The MTT assay showed that adenovirus and $200 \mu M \mathrm{H}_{2} \mathrm{O}_{2}$ did not alter adipocyte viability (Supplemental Figure S3B; https: //doi.org/10.3168/jds.2018-15726). Overexpression of HSPB7 upregulated the protein and mRNA abundance of NFE2L2, and attenuated the effect of $\mathrm{H}_{2} \mathrm{O}_{2}$ on the protein and mRNA abundance of NFE2L2 $(P<0.05$ and $P<0.01$, respectively, Figure 4B, C, and E). Similar trends in mRNA abundance of NFE2L2 downstream target genes HMOX1 and NQO1 were also observed ( $P$ $<0.05$ and $P<0.01$, respectively, Figure $4 \mathrm{~F}$ and $\mathrm{G}$ ). Furthermore, HSPB7 overexpression increased SOD and GSH-Px activity, and attenuated the decrease of SOD and GSH-Px activity induced by $\mathrm{H}_{2} \mathrm{O}_{2}(P<0.01$,
Figure 5A and B). Importantly, HSPB7 overexpression markedly decreased MDA and ROS production, and attenuated the increase of MDA and ROS induced by $\mathrm{H}_{2} \mathrm{O}_{2}(P<0.05$ and $P<0.01$, respectively, Figure $5 \mathrm{C}-\mathrm{E})$.

\section{Effects of HSPB7 Knockdown on Oxidative Stress in Bovine Adipocytes}

The MTT assay showed that siRNA and $200 \mu M$ $\mathrm{H}_{2} \mathrm{O}_{2}$ did not alter adipocyte viability (Supplemental Figure S3C; https://doi.org/10.3168/jds.2018-15726). In contrast to HSPB7 overexpression, HSPB7 knockdown decreased the mRNA and protein abundance of NFE2L2 and mRNA abundance of HMOX1 and $N Q O 1$ and further exacerbated the downregulation of NFE2L2, HMOX1, and NQO1 in $\mathrm{H}_{2} \mathrm{O}_{2}$-treated adipocytes $(P<0.05$ and $P<0.01$, respectively, Figure $6 \mathrm{~A}-\mathrm{G})$. Furthermore, HSPB7 knockdown sharply de-
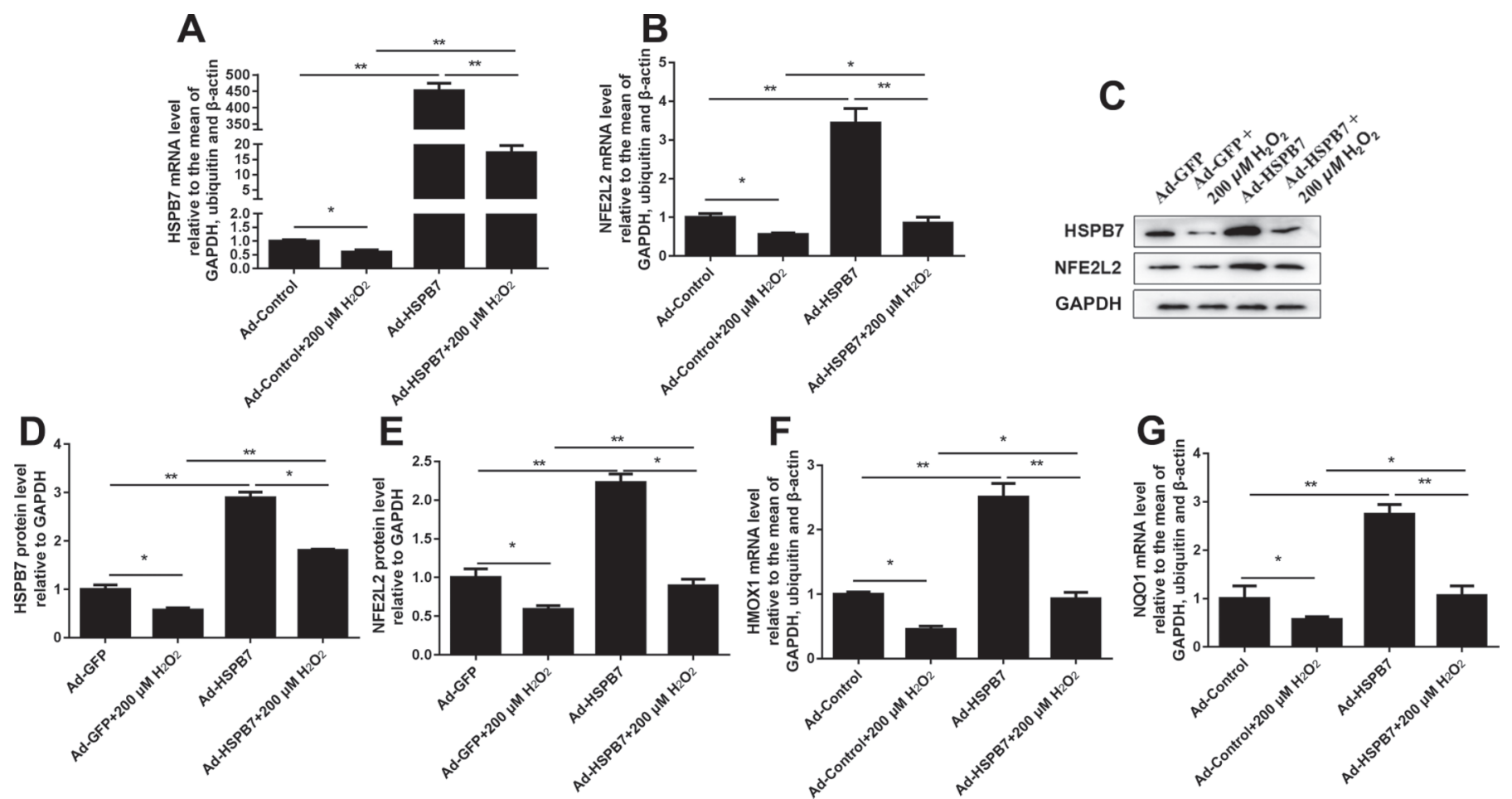

Figure 4. Effect of overexpression of heat-shock protein B7 (HSPB7) on HSPB7 and nuclear factor, erythroid 2 like 2 (NFE2L2) abundance in bovine adipocytes. The cells were divided into 4 groups as follows: an Ad-GFP group (transfected with empty adenovirus vector for $48 \mathrm{~h}$ ), an Ad-GFP $+200 \mu M \mathrm{H}_{2} \mathrm{O}_{2}$ group (transfected with empty adenovirus vector for $48 \mathrm{~h}$ and then treated with $200 \mu M \mathrm{H}_{2} \mathrm{O}_{2}$ for $2 \mathrm{~h}$ ), an Ad-HSPB7 group (transfected with HSPB7 overexpression adenovirus for $48 \mathrm{~h}$ ), and an Ad-HSPB7 $+200 \mu M \mathrm{H}_{2} \mathrm{O}_{2}$ group (transfected with HSPB7 overexpression adenovirus for $48 \mathrm{~h}$ and then treated with $200 \mu M \mathrm{H}_{2} \mathrm{O}_{2}$ for $2 \mathrm{~h}$ ). (A) Relative mRNA expression level of HSPB7, (B) relative mRNA expression level of NFE2L2, (C) Western blot analysis of HSPB7 and NFE2L2, (D) relative protein expression levels of HSPB7, (E) relative protein expression levels of NFE2L2, (F) relative mRNA expression level of heme oxygenase-1 (HMOX1), and (G) relative mRNA expression level of NADH quinone oxidoreductase 1 (NQO1). The data of the Ad-GFP group were used to normalize the data of each treatment group. Comparisons among groups were calculated using a 1-way ANOVA with subsequent Bonferroni correction. The data presented are the mean \pm SEM. ${ }^{*} P<0.05, * * P<0.01$. 
creased SOD and GSH-Px activity but increased MDA and ROS production, and further exacerbated $\mathrm{H}_{2} \mathrm{O}_{2-}$ induced downregulation of SOD and GSH-Px activity and overproduction of MDA and $\operatorname{ROS}(P<0.05$ and $P$ $<0.01$, respectively, Figure 7A-E).

\section{DISCUSSION}

Severe NEB, which initiates fat mobilization, induces stress in adipose tissue and renders peripartal cows susceptible to ketosis (White, 2015; Wankhade et al., 2017; Zhang et al., 2018). In humans and mice, heat shock protein and NFE2L2 act as antioxidant molecules maintaining redox homeostasis in human and mice (Gomer et al., 1996; Sherif, 2018). In this study, the abundance of HSPB7 and NFE2L2 and oxidative stress was greater in adipose tissue of clinically ketotic cows than healthy cows and our in vitro data revealed that HSPB7 protected bovine adipocytes against oxidative stress via the NFE2L2 pathway.

Heat shock proteins can protect cells against oxidative stress by inhibiting ROS production (Chong et al., 1998). Thus, the high levels of HSPB7 gene expression detected in adipose tissues of obese humans (González-
Muniesa et al., 2013) suggested an antioxidant role for HSPB7. In this study, the higher HSPB7 abundance in adipose tissue of clinically ketotic dairy cows may be a compensatory adaptation mechanism to curtail the NEB-induced metabolic stress. The NFE2L2 signaling pathway is a key mechanism of protection of the cell against oxidative stress (Sherif, 2018). Importantly, Zachut et al. (2017) reported that NFE2L2 abundance was upregulated in adipose tissue of heat-stressed dairy cows. Activation of NFE2L2 occurs when the concentrations of electrophiles or ROS increase in the cell. Thus, the fact that we detected a marked upregulation of NFE2L2 abundance in adipose tissue of clinically ketotic dairy cows strongly suggests an upregulation of cytoprotective responses. Pedernera et al. (2010) found that severe NEB was an important factor in a high level of oxidative stress in dairy cows. Ketosis occurs when physiologic mechanisms for the adaptation to NEB fail (Herdt, 2000). A clinical investigation revealed that cows with ketosis displayed systemic signs of oxidative stress (Sahoo et al., 2009). In the present study, the greater MDA content coupled with the lower activity of GSH-Px and SOD, 2 of the most frequently used antioxidant indicators, in clinically ketotic cows confirmed

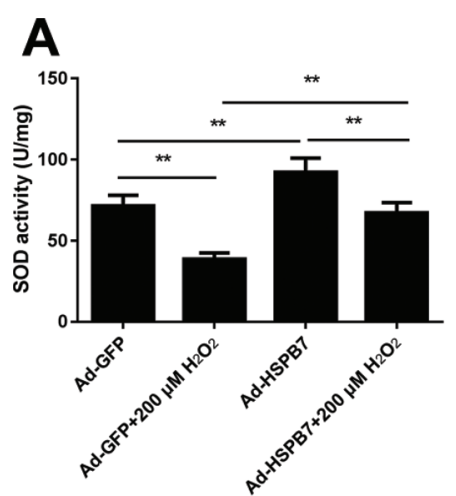

E

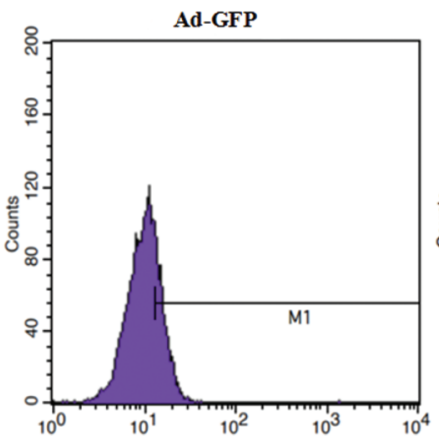

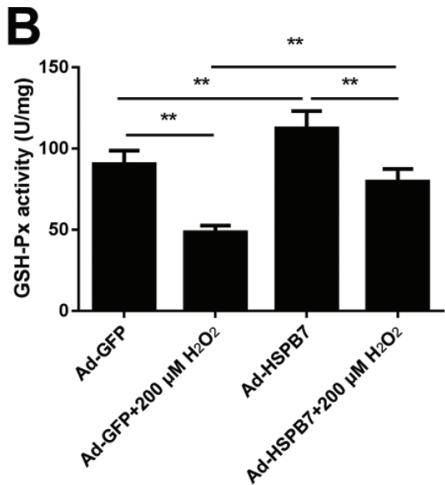

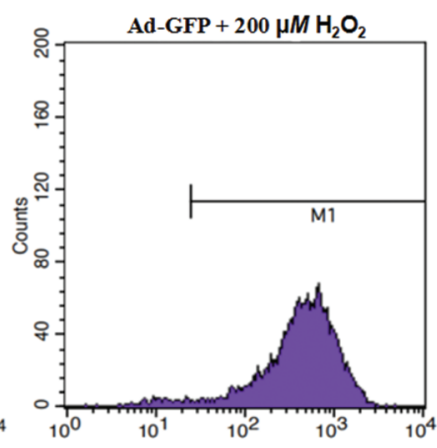

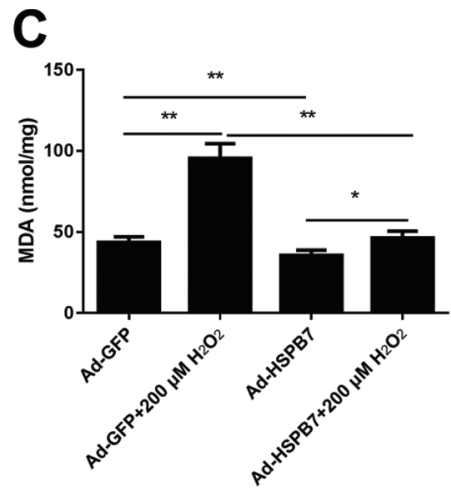
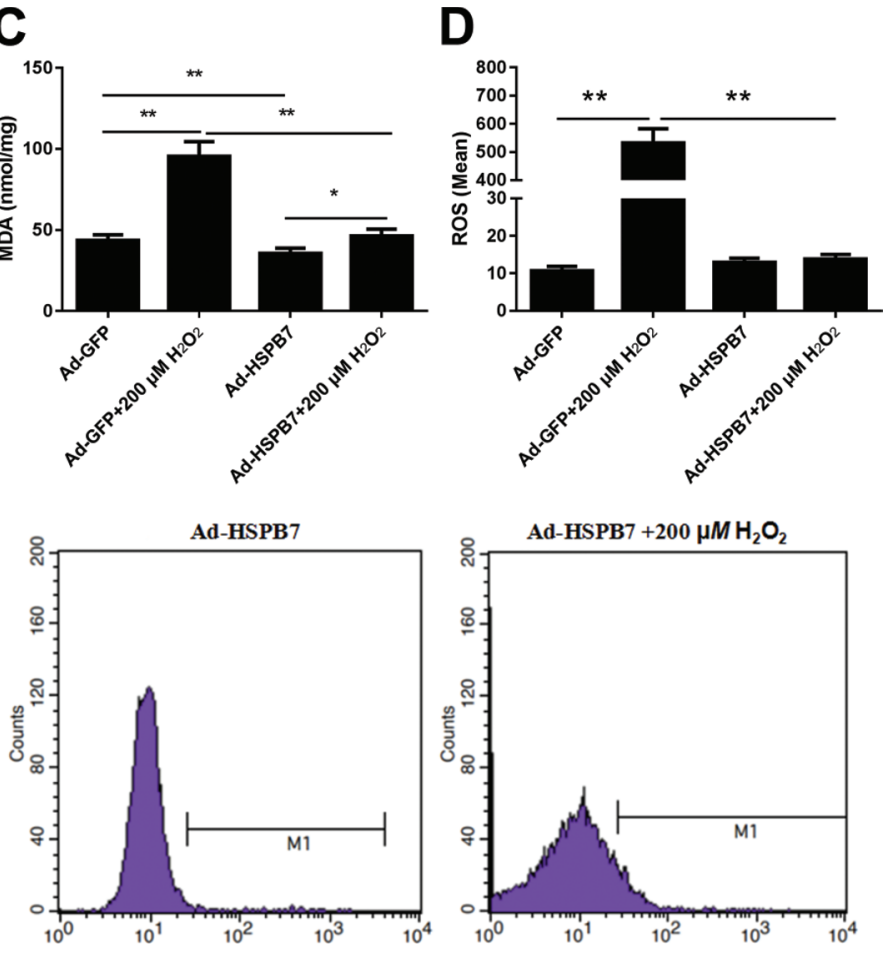

Figure 5. Effect of overexpression of heat-shock protein B7 (HSPB7) on oxidative stress in bovine adipocytes. Cells were treated as in Figure 4. (A) Superoxide dismutase (SOD) activity, (B) glutathione peroxidase (GSH-Px) activity, (C) malondialdehyde (MDA) content, and (D-E) reactive oxygen species $(\mathrm{ROS})$ content. $\mathrm{M} 1=$ proportion of positive cells in 10,000 cells. Comparisons among groups were calculated using a 1 -way ANOVA with subsequent Bonferroni correction. The data presented are the mean \pm SEM. ${ }^{*} P<0.05,{ }^{* *} P<0.01$. 
the greater degree of oxidative stress within adipose tissue. The lower activity of antioxidase may be due to the impairment of antioxidant system in clinically ketotic cows (Du et al., 2017). Furthermore, it is possible that severe metabolic lipolysis-induced oxidative stress exceeded the antioxidant ability in adipose tissue of clinically ketotic cows.

The transcription factor NFE2L2 is a key factor that protects cells from oxidative stress by regulating the transcription of the antioxidant genes (NQO1 and HMOX1; Zachut et al., 2017). The NQO1 is a key oxidative stress response gene under the control of NFE2L2, and has a role in protecting against oxidative stress by scavenging superoxides, preserving various endogenous antioxidants, and catalyzing reductive metabolism of chemicals (Nioi and Hayes, 2004). It has been shown that the induction of NQO1 by some stimulating factors is fully dependent on NFE2L2 (Zhang et al., 2011). HMOX1 is another downstream antioxidant gene of the NFE2L2 that plays an important role in defense mecha- nisms against oxidative damage by metabolizing heme into bilirubin and biliverdin, both of which are important antioxidants in liver (Sherif, 2018) and adipocytes (Wang et al., 2017).

In this study, we found that overexpression of HSPB7 in cultured adipocytes increased the abundance of NFE2L2 and its target genes HMOX1 and NQO1 in bovine adipocytes. Furthermore, HSPB7 overexpression increased the activity of SOD and GSH-Px but inhibited ROS and MDA production. These data indicate that HSPB7 overexpression can activate the NFE2L2 pathway to further increase the cellular antioxidant capacity and maintain redox balance in adipocytes. In contrast to HSPB7 overexpression, HSPB7 knockdown decreased the abundance of NFE2L2, HMOX1, and NQO1 as well as SOD and GSH-Px activity but promoted ROS and MDA production in bovine adipocytes. These data underscored a positive association between HSPB7 and the NFE2L2 pathway. Although the exact mechanisms responsible for this positive associa-
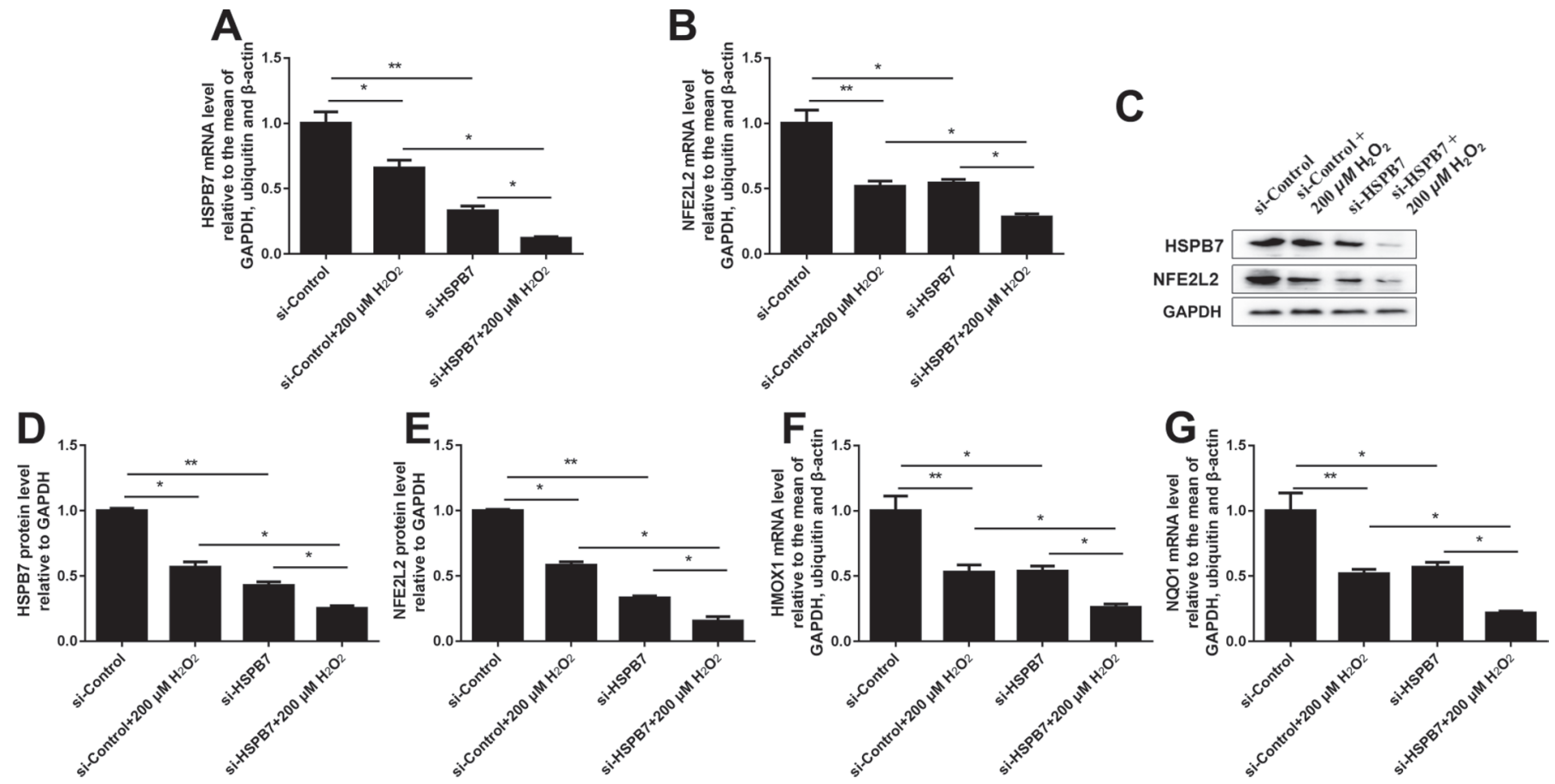

Figure 6. Effect of knockdown of heat-shock protein B7 (HSPB7) on HSPB7 and nuclear factor, erythroid 2 like 2 (NFE2L2) abundance in bovine adipocytes. The cells were divided into 4 groups as follows: an si-Control group [transfected with negative control of small interfering RNA (siRNA) for $48 \mathrm{~h}$ ], an si-Control $+200 \mu M \mathrm{H}_{2} \mathrm{O}_{2}$ group (transfected with negative control of siRNA for $48 \mathrm{~h}$ and then treated with $200 \mu M$ $\mathrm{H}_{2} \mathrm{O}_{2}$ for $2 \mathrm{~h}$ ), an si-HSPB7 group (transfected with siRNA for HSPB7 for $48 \mathrm{~h}$ ), and an Ad-HSPB7 $+200 \mu M \mathrm{H}_{2} \mathrm{O}_{2}$ group (transfected with siRNA for HSPB7 for $48 \mathrm{~h}$ and then treated with $200 \mu M \mathrm{H}_{2} \mathrm{O}_{2}$ for $2 \mathrm{~h}$ ). (A) Relative mRNA expression level of HSPB7, (B) relative mRNA expression level of NFE2L2, (C) Western blot analysis of HSPB7 and NFE2L2, (D) relative protein expression levels of HSPB7, (E) relative protein expression levels of NFE2L2, (F) relative mRNA expression level of heme oxygenase-1 (HMOX1), and (G) relative mRNA expression level of NADH quinone oxidoreductase 1 (NQO1). The data of the si-Control group were used to normalize the data of each treatment group. Comparisons among groups were calculated using a 1-way ANOVA with subsequent Bonferroni correction. The data presented are the mean \pm SEM. ${ }^{*} P<0.05,{ }^{*} P<0.01$. 
tion could not be discerned, the downregulation of the NFE2L2 pathway suggests that HSPB7 can mediate its activation in cow adipocytes.

An imbalance between ROS production and antioxidant defenses can alter normal cell function and results in oxidative stress in dairy cows (Sordillo et al., 2009). In the present study, the increased content of ROS and MDA coupled with the decreased activity of GSH-Px and SOD induced by $\mathrm{H}_{2} \mathrm{O}_{2}$ exceeded the ability of adipocytes to scavenge ROS to prevent oxidative stress. The NFE2L2 pathway is at the forefront of cellular antioxidant defenses (Zhang et al., 2011). Several studies have confirmed that the expression of NFE2L2 and its target antioxidant genes are increased in several types of cells challenged with various oxidants (Ding et al., 2018; Li et al., 2018). In this study, our results showed that a low concentration of $\mathrm{H}_{2} \mathrm{O}_{2}$ increased the abundance of HSPB7, NFE2L2, HMOX1, and NQO1 in bovine adipocytes, which is consistent with the high abundance of HSPB7 and NFE2L2 in adipose tissue of clinically ketotic cows with oxidative stress. These data indicated that activation the HSPB7-NFE2L2 pathway in adipose tissue of clinically ketotic dairy cows augments antioxidant capacity to scavenge ROS. In addition, we found that a high concentration of $\mathrm{H}_{2} \mathrm{O}_{2}$ decreased the abundance of HSPB7, NFE2L2, HMOX1, and NQO1 indicating that high concentrations of $\mathrm{H}_{2} \mathrm{O}_{2}$ inactivated the HSPB7-NFE2L2 pathway. This result may be due to severe oxidative injury caused by high concentrations of $\mathrm{H}_{2} \mathrm{O}_{2}$ exceeding the adipocyte's adaptive ability.

\section{CONCLUSIONS}

In summary, we demonstrated that activation of HSPB7 protects adipocytes from preruminant calves against $\mathrm{H}_{2} \mathrm{O}_{2}$-induced oxidative stress via the NFE2L2 pathway. Our data indicated that overexpression HSPB7 in adipocytes attenuated the decrease of NFE2L2, HMOX1, and NQO1 abundance, and SOD and GSH-Px activity. Furthermore, it attenuated the increase of MDA and ROS induced by $\mathrm{H}_{2} \mathrm{O}_{2}$, thus alleviating $\mathrm{H}_{2} \mathrm{O}_{2}$-induced oxidative stress. Silencing HSPB7 further exacerbated the $\mathrm{H}_{2} \mathrm{O}_{2}$-induced downregulation
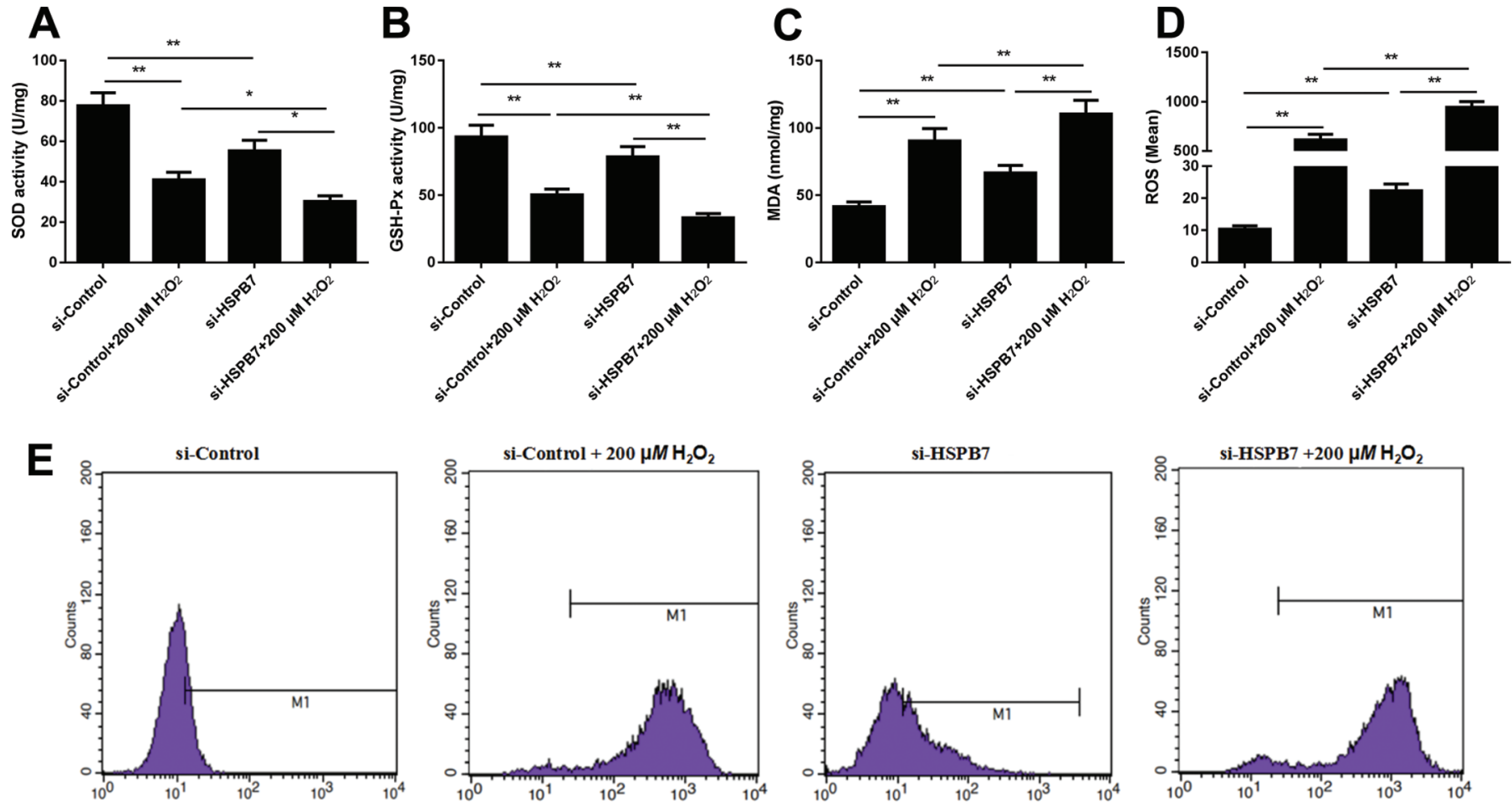

Figure 7. Effect of knockdown of heat-shock protein B7 (HSPB7) on oxidative stress in bovine adipocytes. The cells were divided into 4 groups as follows: an si-Control group [transfected with negative control of small interfering RNA (siRNA) for $48 \mathrm{~h}$ ], an si-Control $+200 \mu M$ $\mathrm{H}_{2} \mathrm{O}_{2}$ group (transfected with negative control of siRNA for $48 \mathrm{~h}$ and then treated with $200 \mu M \mathrm{H}_{2} \mathrm{O}_{2}$ for $2 \mathrm{~h}$ ), an si-HSPB7 group (transfected with siRNA for HSPB7 for $48 \mathrm{~h}$ ), and an Ad-HSPB7 $+200 \mu M \mathrm{H}_{2} \mathrm{O}_{2}$ group (transfected with siRNA for HSPB7 for $48 \mathrm{~h}$ and then treated with $200 \mu \mathrm{M} \mathrm{H}_{2} \mathrm{O}_{2}$ for $2 \mathrm{~h}$ ). (A) Superoxide dismutase (SOD) activity, (B) glutathione peroxidase (GSH-Px) activity, (C) malondialdehyde (MDA) content, and (D-E) reactive oxygen species (ROS) content. M1 = proportion of positive cells in 10,000 cells. Comparisons among groups were calculated using a 1-way ANOVA with subsequent Bonferroni correction. The data presented are the mean \pm SEM. ${ }^{*} P<0.05 ; * * P<0.01$. 
of the NFE2L2 pathway, increasing ROS and MDA concentrations and reducing GSH-Px and SOD activity, which further exacerbated $\mathrm{H}_{2} \mathrm{O}_{2}$-induced oxidative stress. Thus, these data further support the role of the HSPB7-NFE2L2 pathway in the antioxidant response of the adipocytes from preruminant calves. Together, our data indicate that overactivation of HSPB7, in response to oxidative stress, activates the NFE2L2 signaling pathway and enhances antioxidant capacity in adipocytes from preruminant calves. These findings provide new avenues of investigation for the prevention and treatment of cows with clinical ketosis. However, there may be many differences in metabolic and physiological characteristics between the newborn calf adipogenic model and adipocytes of ketosis cows. Thus, results from this study should be translated to adipocytes from transition cows and ketotic cows. Further research should be focused on the role of HSPB7 in the transition cow adipogenic model as well as in adipose tissue of ketotic cows to better address the relevance of the present findings.

\section{ACKNOWLEDGMENTS}

This work was supported by the National Key Research and Development Program (Beijing, China; grant no. 2016YFD0501007), National Natural Science Foundation of China (Beijing, China; grant no. 31772810, 31572581, and 31672621), Jilin Province Science Foundation for Youths (Changchun, China; grant no. 20160520063JH), and Natural Science Foundation of Jilin Province (Changchun, China, grant no. 20170101148JC). There are no conflicts of interest.

\section{REFERENCES}

Bernabucci, U., B. Ronchi, N. Lacetera, and A. Nardone. 2005. Influence of body condition score on the relationship between metabolic status and oxidative stress in periparturient dairy cows. J. Dairy Sci. 88:2017-2026.

Bustin, S. A., V. Benes, J. A. Garson, J. Hellemans, J. Huggett, M. Kubista, R. Mueller, T. Nolan, M. W. Pfaffl, G. L. Shipley, J. Vandesompele, and C. T. Wittwer. 2009. The MIQE guidelines: Minimum information for publication of quantitative real-time PCR experiments. Clin. Chem. 55:4. https://doi.org/10.1373/ clinchem.2008.112797.

Chong, K. Y., C. C. Lai, S. Lille, C. Chang, and C. Y. Su. 1998. Stable overexpression of the constitutive form of heat shock protein 70 confers oxidative protection. J. Mol. Cell. Cardiol. 30:599-608.

Ding, S., X. Hou, F. Wang, G. Wang, X. Tan, Y. Liu, Y. Zhou, H. Qiu, E. Sun, N. Jiang, Z. Li, J. Song, L. Feng, and X. Jia. 2018. Regulation of Eclipta prostrata L. components on cigarette smoking-induced autophagy of bronchial epithelial cells via keap1-Nrf2 pathway. Environ. Toxicol. https://doi.org/10.1002/tox.22567.

Du, X., Z. Shi, Z. Peng, C. Zhao, Y. Zhang, Z. Wang, X. Li, G. Liu, and X. Li. 2017. Acetoacetate induces hepatocytes apoptosis by the ROS-mediated MAPKs pathway in ketotic cows. J. Cell. Physiol. 232:3296-3308.
Du, X., Y. Zhu, Z. Peng, Y. Cui, Q. Zhang, Z. Shi, Y. Guan, X. Sha, T. Shen, Y. Yang, X. Li, Z. Wang, X. Li, and G. Liu. 2018. High concentrations of fatty acids and $\beta$-hydroxybutyrate impair the growth hormone-mediated hepatic JAK2-STAT5 pathway in clinically ketotic cows. J. Dairy Sci. 101:3476-3487.

Gomer, C. J., S. W. Ryter, A. Ferrario, N. Rucker, S. Wong, and A. M. Fisher. 1996. Photodynamic therapy-mediated oxidative stress can induce expression of heat shock proteins. Cancer Res. $56: 2355-2360$.

González-Muniesa, P., M. P. Marrades, J. A. Martínez, and M. J. Moreno-Aliaga. 2013. Differential proinflammatory and oxidative stress response and vulnerability to metabolic syndrome in habitual high-fat young male consumers putatively predisposed by their genetic background. Int. J. Mol. Sci. 14:17238-17255.

Grummer, R. R. 1993. Etiology of lipid-related metabolic disorders in periparturient dairy cows. J. Dairy Sci. 76:3882-3896.

Herdt, T. H. 2000. Ruminant adaptation to negative energy balance. Influences on the etiology of ketosis and fatty liver. Vet. Clin. North Am. Food Anim. Pract. 16:215-230.

Itle, A. J., J. M. Huzzey, D. M. Weary, and M. A. von Keyserlingk. 2015. Clinical ketosis and standing behavior in transition cows. J. Dairy Sci. 98:128-134.

Jung, K. A., and M. K. Kwak. 2010. The Nrf2 system as a potential target for the development of indirect antioxidants. Molecules 15:7266-7291.

Karttunen, M., W. Y. Choy, and E. A. Cino. 2018. Prediction of binding energy of Keap1 interaction motifs in the Nrf2 antioxidant pathway and design of potential high-affinity peptides. J. Phys. Chem. B 122:5851-5859.

Krief, S., J. F. Faivre, P. Robert, B. Le Douarin, N. Brument-Larignon, I. Lefrère, M. M. Bouzyk, K. M. Anderson, L. D. Greller, F. L. Tobin, M. Souchet, and A. Bril. 1999. Identification and characterization of cvHsp. A novel human small stress protein selectively expressed in cardiovascular and insulin-sensitive tissues. J. Biol. Chem. 274:36592-36600.

Lee, Y. J., and P. M. Corry. 1998. Metabolic oxidative stress-induced HSP70 gene expression is mediated through SAPK pathway. Role of Bcl-2 and c-Jun NH2-terminal kinase. J. Biol. Chem. 273:29857-29863.

Li, J., L. Li, and S. Wang. 2018. Resveratrol alleviates inflammatory responses and oxidative stress in rat kidney ischemia-reperfusion injury and $\mathrm{H}_{2} \mathrm{O}_{2}$-induced NRK-52E cells via the Nrf2/TLR $4 / \mathrm{NF}$ $\kappa \mathrm{B}$ pathway. Cell. Physiol. Biochem 45:1677-1689.

Li, Y., H. Y. Ding, X. C. Wang, S. B. Feng, X. B. Li, Z. Wang, G. W. Liu, and X. W. Li. 2016. An association between the level of oxidative stress and the concentrations of NEFA and BHBA in the plasma of ketotic dairy cows. J. Anim. Physiol. Anim. Nutr. (Berl.) 100:844-851.

Loor, J. J., R. E. Everts, M. Bionaz, H. M. Dann, D. E. Morin, R. Oliveira, S. L. Rodriguez-Zas, J. K. Drackley, and H. A. Lewin. 2007. Nutrition-induced ketosis alters metabolic and signaling gene networks in liver of periparturient dairy cows. Physiol. Genomics 32:105-116.

Morimoto, R. I., and M. G. Santoro. 1998. Stress-inducible responses and heat shock proteins: New pharmacologic targets for cytoprotection. Nat. Biotechnol. 16:833-838.

Nioi, P., and J. D. Hayes. 2004. Contribution of NAD(P)H:quinone oxidoreductase 1 to protection against carcinogenesis, and regulation of its gene by the Nrf2 basic-region leucine zipper and the arylhydrocarbon receptor basic helix-loop-helix transcription factors. Mutat. Res. 555:149-171.

Park, J. R., J. W. Jung, M. S. Seo, S. K. Kang, Y. S. Lee, and K. S. Kang. 2010. DNER modulates adipogenesis of human adipose tissue-derived mesenchymal stem cells via regulation of cell proliferation. Cell Prolif. 43:19-28.

Pedernera, M., P. Celi, S. C. García, H. E. Salvin, I. Barchia, and W. J. Fulkerson. 2010. Effect of diet, energy balance and milk production on oxidative stress in early-lactating dairy cows grazing pasture. Vet. J. 186:352-357. 
Roche, J. R., A. W. Bell, T. R. Overton, and J. J. Loor. 2013. Nutritional management of the transition cow in the 21st century - A paradigm shift in thinking. Anim. Prod. Sci. 53:1000-1023.

Sahoo, S. S., R. C. Patra, P. C. Behera, and D. Swarup. 2009. Oxidative stress indices in the erythrocytes from lactating cows after treatment for subclinical ketosis with antioxidant incorporated in the therapeutic regime. Vet. Res. Commun. 33:281-290.

Salo, D. C., C. M. Donovan, and K. J. Davies. 1991. HSP70 and other possible heat shock or oxidative stress proteins are induced in skeletal muscle, heart, and liver during exercise. Free Radic. Biol. Med. 11:239-246.

Sherif, I. O. 2018. The effect of natural antioxidants in cyclophosphamide-induced hepatotoxicity: Role of Nrf2/HO-1 pathway. Int. Immunopharmacol. 61:29-36.

Sordillo, L. M., G. A. Contreras, and S. L. Aitken. 2009. Metabolic factors affecting the inflammatory response of periparturient dairy cows. Anim. Health Res. Rev. 10:53-63.

van der Drift, S. G., M. Houweling, M. Bouman, A. P. Koets, A. G. Tielens, M. Nielen, and R. Jorritsma. 2015. Effects of a single glucocorticoid injection on propylene glycol-treated cows with clinical ketosis. Vet. J. 204:144-149.

Verschuure, P., C. Tatard, W. C. Boelens, J. F. Grongnet, and J. C. David. 2003. Expression of small heat shock proteins HspB2, HspB8, Hsp20 and cvHsp in different tissues of the perinatal developing pig. Eur. J. Cell Biol. 82:523-530.

Wang, Z., S. O. Ka, Y. Lee, B. H. Park, and E. J. Bae. 2017. Butein induction of HO-1 by p38 MAPK/Nrf2 pathway in adipocytes attenuates high-fat diet induced adipose hypertrophy in mice. Eur. J. Pharmacol. 799:201-210.
Wankhade, P. R., A. Manimaran, A. Kumaresan, S. Jeyakumar, K. P. Ramesha, V. Sejian, D. Rajendran, and M. R. Varghese. 2017. Metabolic and immunological changes in transition dairy cows: A review. Vet. World 10:1367-1377.

White, H. M. 2015. The role of TCA cycle anaplerosis in ketosis and fatty liver in periparturient dairy cows. Animals (Basel) 5:793-802.

Yang, Z., Y. Wang, Y. Lu, and X. Zhao. 2011. Molecular characterization of rat cvHsp/Hspb7 in vitro and its dynamic molecular architecture. Mol. Med. Rep. 4:105-111.

Yin, L., X. Qin, Q. Deng, Y. Zhang, L. Lei, and W. Gao. 2015. The isolation of pre-adipocytes from dairy cow adipose tissue and the development of pre-adipocytes into mature adipocytes. Pak. Vet. J. 35:283-288.

Youssef, M., and M. El-Ashker. 2017. Significance of insulin resistance and oxidative stress in dairy cattle with subclinical ketosis during the transition period. Trop. Anim. Health Prod. 49:239-244.

Zachut, M., G. Kra, L. Livshitz, Y. Portnick, S. Yakoby, G. Friedlander, and Y. Levin. 2017. Seasonal heat stress affects adipose tissue proteome toward enrichment of the Nrf2-mediated oxidative stress response in late-pregnant dairy cows. J. Proteomics 158:52-61.

Zhang, S., G. Liu, C. Xu, L. Liu, Q. Zhang, Q. Xu, H. Jia, X. Li, and X. Li. 2018. Perilipin 1 mediates lipid metabolism homeostasis and inhibits inflammatory cytokine synthesis in bovine adipocytes. Front. Immunol. 9:467.

Zhang, Y., Y. H. Ahn, I. J. Benjamin, T. Honda, R. J. Hicks, V. Calabrese, P. A. Cole, and A. T. Dinkova-Kostova. 2011. HSF1dependent upregulation of Hsp70 by sulfhydryl-reactive inducers of the KEAP1/NRF2/ARE pathway. Chem. Biol. 18:1355-1361. 